\title{
A refuge for scientists' writings
}

\author{
Professor Margaret Gowing, Honorary Director of the \\ Contemporary Scientific Archives Centre, Oxford, explains how \\ the centre was set up and outlines its work
}

History is essential to society and science and technology are crucial ingredients of history. History depends on records and therefore scientific and technological records should be systematically preserved. Until recently however records of 20th century scientists and engineers attracted much less interest than those of, say, politicians or novelists.

Most scientists and engineers work in institutions-government establishments, industrial firms or universitiesand if all these institutions systematically gathered and retained records the residual problem would be small. But many of them do not. Thus, few British universities have archives staff and fewer still gather the papers of academics as they retire or die.

For these reasons, the Royal Society established a Committee on Scientific and Technological Records in 1967, under the chairmanship first of Sir Harold Hartley and then of Professor Nicholas Kurti. In 1969 a conference called by the committee agreed that scientists' and engineers' papers required special action, partly because general archives tended to be frightened by them. It was further agreed to establish not a special archive but a centre which would locate, sort and catalogue the papers of individual eminent scientists and engineers. Each collection would then be permanently deposited in an appropriate existing library and only the catalogues, reproduced by the Royal Commission on Historical Manuscripts, would be kept centrally and in the copyright libraries. The Wolfson Foundation gave a grant for an experimental period and I was asked to establish a centre at Oxford, where I had just been appointed Professor of the History of Science.

The Contemporary Scientific Archives Centre started in one basement room in April 1973 and has had a total paid staff of two people who do everything from typing, stamp-licking and driving to collect papers, to producing scholarly catalogues and orderly boxed collections, often from extensive and chaotic manuscripts. By the end of August 197860 collections had been handed over to 29 different libraries and a further 14 collections were in hand. In addition 175 enquiries had been made. The list at the end shows the variety of disciplines covered.

The collections cover scientists (including medical scientists) and engineers who died after the Second World
War. The danger point for dispersal of papers is usually retirement but because of shortage of resources the centre can only deal with a very few collections of people as they retire. The Royal Society Committee decides who shall be included but the list is not confined to Fellows of the Royal Society nor do all Fellows automatically qualify.

By 'papers' the centre does not mean only scientific publications. The word includes papers of all kinds such as notebooks, notes of lectures heard or delivered, papers and correspondence covering all stages and all aspects of a scientist's life from school reports to political activity. The collections vary greatly in size and context. Some scientists keep few papers and some papers regrettably disappear: for example, the contents of the filing cabinets of Nobel prizewinner Cecil Powell, the physicist, were shredded soon after his death. By contrast some collections are very large, cover many years and are of outstanding interest: for example the papers of physicist Rudolf Peierls (including a life-long correspondence with Neils Bohr and Hans Bethe); Charles Coulson (including, besides papers on chemistry and mathematics, his many concerns such as pacifism, Oxfam and Christianity) or Patrick Blackett, the physicist (including his scientific, wartime, Labour Party and overseas activities). Some collections are beginning to form a

'critical mass' for the history of a discipline-for example in computing science.

The formula for the centre has proved very cost-effective, while Oxford University has helped greatly with administrative services and accommodation. Location in Oxford has also brought unstinting help and advice from many individuals. Nevertheless finance has been a constant anxiety, for the initial grants from the Wolfson Foundation and other funds were pump primers. At present the Royal Society and the British Library share the main cost with a smaller grant from the Council of Engineering Institutions. For two years from 1979 the Wellcome Trust will replace the British Library grant.

The centre has blazed a trail. Neither of the two staff members had any previous archival or scientific training but their work has been outstanding in quality and quantity and has attracted considerable interest abroad, especially in North America. The Wellcome Trust is now itself establishing a project on similar lines for medical practitioners and medical-related scientists. The work is becoming more valuable as more professional groupssuch as various sections of physicists, molecular biologists, and computer scientists-become increasingly interested in the recent history of their disciplines and as more historians study not only the purely scientific work but the other public work and private interests of scientists and engineers.

For further information and copies of Progress Reports (April and October annually) please write to Mrs Alton, Deputy Director, CSAC, 10 Keble Road, Oxford.

\section{Collections completed and $*_{\text {in }}$ hand}

Physics and Theoretical Physics

*Sir Edward Appleton, *I. F. Bates,

*Lord Blackett, *H. A. H. Boot,

S. Chapman, W. Cochrane, H. T. Flint,

H. Heywood, H. London, Sir Rudolf

Peierls, C. F. Powell, A. P. Rowe, Sir

Frank Smith, E. C. Stoner, Sir Geoffrey

Taylor, S. Tolansky, Sir John Townsend,

R. Whiddington

Chemistry and Theoretical Chemistry

C. A. Coulson, Sir Cyril Hinshelwood,

Linstead, *Sir Eric Rideal, *Sir Robert

Robinson, N. V. Sidgwick, F. Soddy

Mathematics (including Mathematics of Computation)

British Association Mathematical Tables Committee, T. M. Chaundy, B. Egerton, S. Gill, D. R. Hartree, *C. Strachey, J. H. C. Thompson, A. E. Titchmarsh, A. M. Turing, F. J. W. Whipple

Biological and Zoological Sciences W. T. Astbury, *J. R. Baker, D. Cunningham, H. M. Fox, Sir James Gray, E. J. Hanson, H. Hewer, E. Hindle, D. Keilin, D. Lack,
Sir Wilfred Le Gros Clark, R. E. Moreau, *A. G. Ogston, *T. Weis-Fogh, *D. D. Woods

\section{Medical Sciences}

Sir Frederick Bartlett, Sir Roy Cameron, J. Cunningham, I. de Burgh Daly,

N. M. Dott, Sir Wilfred Fish,

G. W. Harris, D. Kirby, Sir Charles Lovatt Evans, R. Stacey, Sir Francis Walshe

\section{Engineering}

Sir Hugh Beaver, Lord Jackson, Sir Leonard Owen, E. A. Watson, *C. A. J. Young

Botanical and Agricultural Sciences Sir Frederick Bawden, H. Hunter, W. Stiles

Geography and Geology

H. J. Fleure, *R. G. S. Hudson

Metallurgy

W. Hume-Rothery

History of Science

H. T. Pledge 